\title{
Behavioral hypothermia of a domesticated lizard under treatment of the hypometabolic agent 3-iodothyronamine
}

\author{
Kyoungbong HA ${ }^{1)}$, Haksup SHIN ${ }^{1)}$, Hyunwoo JU ${ }^{1)}$, Chan-Moon $\mathrm{CHUNG}^{2)}$, and Inho CHOI ${ }^{1)}$ \\ 1)Division of Biological Science and Technology, College of Science and Technology, Yonsei University, Wonju, \\ Gangwon-do, 26493, Republic of Korea \\ ${ }^{2}$ Department of Chemistry and Medical Chemistry, College of Science and Technology, Yonsei University, Wonju, \\ Gangwon-do, 26493 Republic of Korea
}

\begin{abstract}
Ectothermic animals rely on behavioral thermoregulation due to low capacity of heat production and storage. Previously, lizards were shown to achieve 'fever' during microbial infection by increasing their preferred body temperature (PBT) behaviorally, thereby attaining a relatively high survival rate. The purpose of this study was to investigate whether domesticated lizards pursued 'behavioral hypothermia' induced by a hypometabolic agent 3-iodothyronamine (T1AM). We found that treatment with $8.0 \mathrm{mg} / \mathrm{kg}$ T1AM caused a lizard species, the leopard gecko (Eublepharis macularius), to decrease its ventilation and oxygen consumption rates 0.64 - and 0.76 -fold, respectively, compared to those of the control $(P<0.05)$. The lizards, habituated at an ambient temperature of 30 $\pm 0.5^{\circ} \mathrm{C}$, also showed a significant decrease in the $\mathrm{PBT}$ range over a freely accessible thermal gradient between $5^{\circ} \mathrm{C}$ and $45^{\circ} \mathrm{C}$. The upper limit of the PBT in the treated lizards lowered from $31.9^{\circ} \mathrm{C}$ to $30.6^{\circ} \mathrm{C}$, and the lower limit from $29.5^{\circ} \mathrm{C}$ to $26.3^{\circ} \mathrm{C}(P<0.001)$. These findings demonstrate that the treated lizards pursued behavioral hypothermia in conjunction with hypoventilation and hypometabolism. Because prior studies reported a similar hypometabolic response in T1AM-injected laboratory mice, the domesticated lizards, as a part of the vertebrate phylogeny, may be a useful laboratory model for biological and pharmacological researches such as drug potency test.
\end{abstract}

Key words: 3-lodothyronamine, behavioral hypothermia, lizards, metabolism, thermoregulation

\section{Introduction}

The regulation of body temperature $\left(\mathrm{T}_{\mathrm{b}}\right)$ is crucial for animals to maintain homeostasis to ensure optimal function and a high probability of survival $[5,7,17]$. Although a large difference exists in physiological thermoregulatory capacity (e.g., heat generation and storage) between ectothermic and endothermic vertebrates, the principal mechanism of thermoregulation appears to be shared in the vertebrate phylogeny $[2,17,19]$. Fever and hypothermia are special physiological mechanisms for survival in critical conditions such as those resulting from microbial infection or external stressors $[4,16]$. The two mechanisms may thus provide a good opportunity to examine the hypothesis that the basis of thermoregulation is conserved in the vertebrates. A representative example is seen in fever, a form of hyperthermia produced by the endogenous pyrogens of the host in response to bacterial endotoxins. An important finding is that the desert iguana (Dipsosaurus dorsalis) induced fever after bacterial infection by raising their preferred body temperature (PBT) behaviorally, leading to an

(Received 22 August 2016 / Accepted 11 October 2016 / Published online in J-STAGE 31 October 2016)

Address corresponding: I. Choi, Division of Biological Science and Technology, Yonsei University, 1 Yonseidaegil, Wonju, Gangwon-do 26493, Republic of Korea

C2017 Japanese Association for Laboratory Animal Science 
increase in survival rate [18]. By analogy with behavioral fever in lizards, we may ask whether ectotherms voluntarily induce 'behavioral hypothermia' in accordance with a well-defined hypometabolic state (see below).

Previous reports have shown that hypometabolism and hypothermia can be induced in non-hibernator rodents by administration of brain extracts from hibernating animals [15] or of certain chemicals, such as 3-iodothyronamine (T1AM) and $\mathrm{H}_{2} \mathrm{~S}[1,14]$. For instance, mice treated with a single dose of T1 AM reduced their metabolic rate until $\mathrm{T}_{\mathrm{b}}$ decreased to $\sim 30^{\circ} \mathrm{C}$ over the first 90 $\sim 120 \mathrm{~min}$ of exposure [11]. Normothermia was then gradually restored 4 to $6 \mathrm{~h}$ after injection. Another comparable example is seen in the administration of $\mathrm{H}_{2} \mathrm{~S}$ to mice. Interestingly, the same substance (in the form of $\mathrm{Na}_{2} \mathrm{~S}$ ) also produced hypometabolic and hypoventilatory effects in a fish, the blue cod (Parapercis colias) [6]. In the fish study, however, because the water (thus body) temperature was maintained at a constant value, it is not known whether the individuals would voluntarily reduce $T_{b}$ to produce a hypometabolic response.

In the current study, we injected T1 AM into the leopard gecko (Eublepharis macularius) to investigate whether the chemical affects the metabolic and thermoregulatory activity of this organism. T1 AM is known to be naturally produced by the enzymatic deiodination and decarboxylation of thyroid hormone T4 [13]. T1AM has been found to trigger a hypometabolic response of target cells via a specific transmembrane receptor such as Gprotein-coupled receptor (e.g., trace amine-associated receptor 1, TAAR1) [14]. As deiodinase, decarboxylase and TAARs are found in most vertebrates [8-10], it is presumed that the interaction of T1 AM with the receptor is conserved in the vertebrates. We therefore tested the hypothesis that the T1AM-treated lizards induce hypothermia behaviorally over a freely exploitable thermal gradient. The results of this study may fill the gap in the current knowledge of the fundamental thermoregulatory mechanism of the ectotherms. The results will also give an opportunity to examine whether the domesticated reptiles can be used as a laboratory model for biological and pharmacological researches. These issues have been overlooked to date.

\section{Material and Methods}

\section{Animals}

This study was carried out in accordance with the Guide for the Animal Care and Use of the Committee on the Ethics of Animal Experiments of Yonsei University Wonju Campus. The protocol was approved by the Committee on the Ethics of Animal Experiments of Yonsei University (Permit Number: YWC-130115-2). Leopard geckos (E. macularius; $18.9 \pm 2.1 \mathrm{~g}, \mathrm{n}=26,1$ year old) were purchased from a local supplier. Before the experiments, all the subjects were habituated for a week under a light:dark cycle of 12:12 h with lights on 07:00, a relative humidity of $\sim 40 \%$ and a cage temperature of $30 \pm 0.5^{\circ} \mathrm{C}$ maintained with a heating pad under one side of the cage. The animals were fed daily with a diet of gut-loaded mealworms supplied at night. All the experiments were conducted after 19:00 as these geckos are nocturnal.

\section{Ventilation rate}

To determine an appropriate dose of T1AM, the ventilation rate (VR, counts per min) was first tested at four different doses injected intraperitoneally (i.p.) in $2-3$ subjects per group: $0 \mathrm{mg} / \mathrm{kg}$ (vehicle control), $4 \mathrm{mg} / \mathrm{kg}$, $8 \mathrm{mg} / \mathrm{kg}$ and $16 \mathrm{mg} / \mathrm{kg}$. Each of the doses was dissolved in $60 \%$ dimethyl sulfoxide (DMSO) and $40 \%$ saline (pH 7.4) [14]. The VR was measured by counting the number of thoracic movements every $10 \mathrm{~min}$ for the first hour and subsequently every $30 \mathrm{~min}$ until the end of the experiment. The dose of $8 \mathrm{mg} / \mathrm{kg}$ T1 AM was chosen as an appropriate one because the subjects did not further decrease the VR at 16 versus $8 \mathrm{mg} / \mathrm{kg}$ (see below in the Results), and because prior observations showed that rodent subjects often died at relatively high doses during experiments, possibly due to a prolonged bradycardia [14]. Once the protocol was decided, the VR was determined with six to eight lizards by injecting the vehicle or T1AM.

\section{Oxygen consumption rate}

The general procedure for measurements of oxygen consumption rate $\left(\mathrm{VO}_{2}\right)$ was described in our previous reports $[11,12]$. The six lizards were fasted for $24 \mathrm{~h}$ before the experiment. An individual subject was placed in a $340-\mathrm{ml}$ metabolic chamber set at $30 \pm 0.5^{\circ} \mathrm{C}$. The subject was stabilized for $1 \mathrm{~h}$ in the chamber and was injected i.p. with either DMSO or T1 AM $\left(8 \mathrm{mg} \mathrm{kg}^{-1}\right)$. 

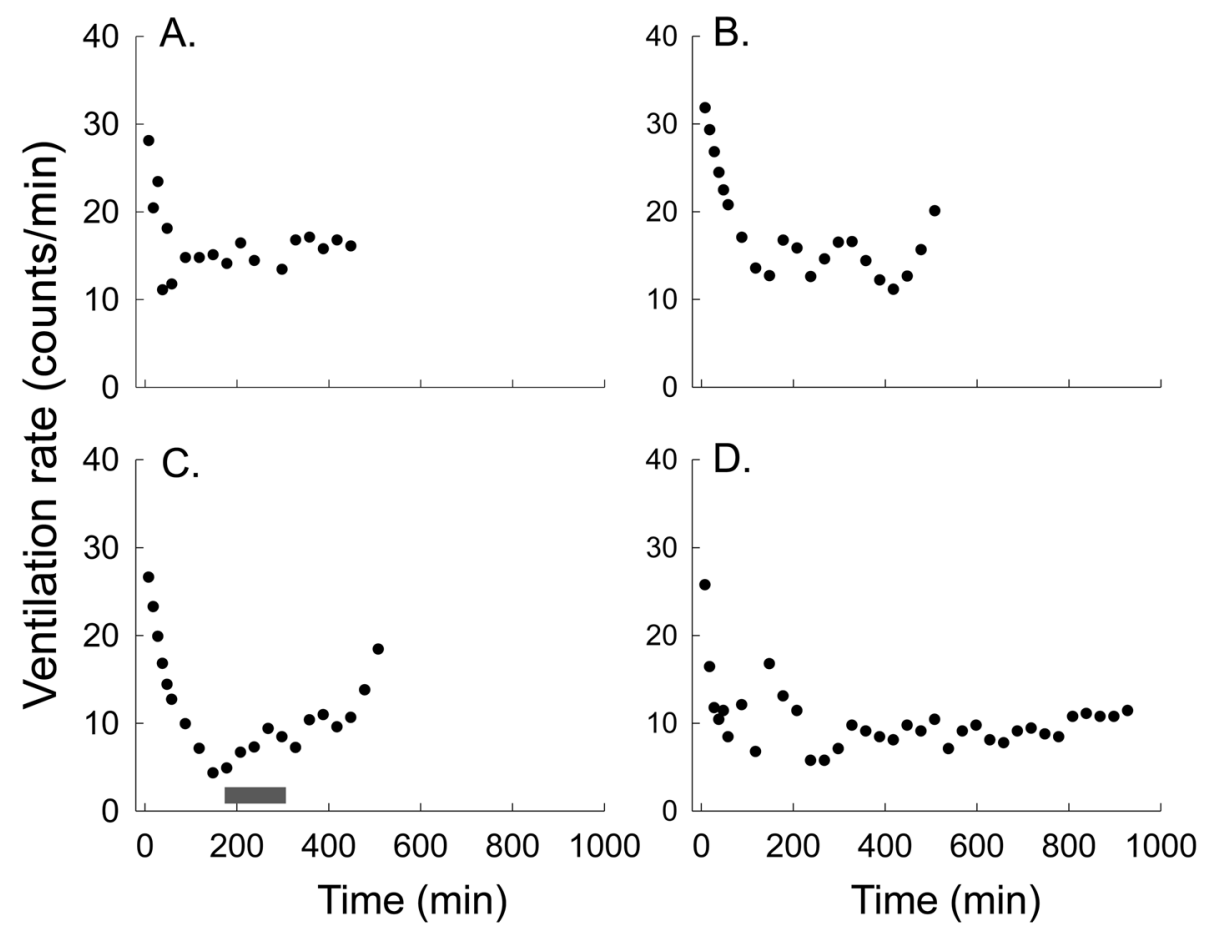

Fig. 1. Representative records of ventilation rates of leopard geckos treated with only DMSO (vehicle control) (A) or T1 AM at dosages (mg/kg) 4.0 (B), 8.0 (C) and 16.0 (D). Data of the time period from 180 to $300 \mathrm{~min}$ were used for the statistical analysis (indicated in $\mathrm{C}$ with a gray bar on the $\mathrm{x}$-axis).

The $\mathrm{VO}_{2}$ data were collected every 10 min with an Oxymax System (Columbus Instruments, Columbus, $\mathrm{OH}$, USA) that included an automated, open-circuit equalflow system connected to the metabolic chamber. The incurrent air supplied to the chamber was set at 550 $\mathrm{ml} / \mathrm{min}$. Excurrent air subsamples were collected at 500 $\mathrm{ml} / \mathrm{min}$, diverted through desiccant columns and sent to the $\mathrm{O}_{2}$ sensor. The gas analyzer signals were transmitted to a personal computer. The $\mathrm{VO}_{2}$ was calculated according to a Hill's equation, expressed as a mass-specific value and corrected to standard temperature $\left(0^{\circ} \mathrm{C}\right)$ and pressure (760 Torr).

\section{Preferred body temperature}

The PBT of the lizards was measured over a thermal gradient between $5^{\circ} \mathrm{C}$ and $45^{\circ} \mathrm{C}$ set up on a copper plate $(\mathrm{W} \times \mathrm{L} \times \mathrm{T}=70 \mathrm{~mm} \times 905 \mathrm{~mm} \times 5 \mathrm{~mm})$. This plate was surrounded by $170-\mathrm{mm}$ high acrylic plates to isolate the subjects from the external environment. To generate the thermal gradient, one end of the copper plate was warmed by a controlled heat block and the other end cooled by a circulator containing an anti-freeze mixture. After the setting was completed, the $T_{b}$ of each lizard was monitored with a 49 AWG (0.025 mm diameter) duplex copperconstantan thermocouple (California Fine Wire, Grover City, CA, USA) connected to a digital thermometer (ColePalmer Instrument, Vernon Hills, IL, USA). The sensing tip of the thermocouple was inserted $7 \mathrm{~mm}$ deep into the latissimus dorsi muscle. The subject was then injected i.p. with the vehicle or T1AM, and was placed randomly on either the warm or the cool end of the copper plate.

\section{Statistical analysis}

The data are presented as mean $\pm \mathrm{SD}$. The significance of differences in VR between groups was tested via independent samples $t$-tests. Differences in $\mathrm{VO}_{2}$ and PBT between treatments were assessed via paired-samples $t$-tests. The procedure was performed with SPSS/PC+, and significance was accepted at the level of $P<0.05$.

\section{Results}

The VR of the control animals stabilized at a level of 13 to $17 \mathrm{CPM}$ within $30 \mathrm{~min}$ of DMSO injection (Fig. 1). The VR decreased slightly further at a dose of 4 $\mathrm{mg} / \mathrm{kg}$ T1AM, but decreased considerably to $4 \sim 10$ 
Table 1. Summary data for ventilation rate, oxygen consumption rate and up-

\begin{tabular}{|c|c|c|}
\hline Variables & Control $^{2}$ & $\mathrm{~T} 1 \mathrm{AM}^{2}$ \\
\hline \multicolumn{3}{|l|}{ Ventilation rate (counts/min) } \\
\hline Average VR* & $11.6 \pm 1.9$ & $7.4 \pm 1.6$ \\
\hline${ }^{1}$ Minimum VR* & $\begin{array}{c}8.9 \pm 2.1 \\
(\mathrm{n}=6)\end{array}$ & $\begin{array}{c}3.0 \pm 2.8 \\
(\mathrm{n}=8)\end{array}$ \\
\hline \multirow[t]{2}{*}{ Oxygen consumption rate ${ }^{\dagger}(\mathrm{ml} / \mathrm{g} / \mathrm{h})$} & $0.075 \pm 0.011$ & $0.056 \pm 0.014$ \\
\hline & \multicolumn{2}{|c|}{$(n=6)$} \\
\hline \multicolumn{3}{|l|}{ Preferred body temperature $\left({ }^{\circ} \mathrm{C}\right)$} \\
\hline Upper limit (UL) & $31.9 \pm 0.5$ & $30.6 \pm 1.7$ \\
\hline \multirow[t]{2}{*}{ Lower limit (LL) } & $29.5 \pm 1.3$ & $26.3 \pm 1.1$ \\
\hline & \multicolumn{2}{|c|}{$(\mathrm{n}=6)$} \\
\hline
\end{tabular}

Data: mean \pm SD. ${ }^{1}$ Minimum VR is the mean of the single lowest VRs of individual subjects over 180 to 300 min post-injection. ${ }^{2}$ Significance of differences between DMSO and T1AM treatments: *, $P<0.001$ (independent $t$-test); ${ }^{\dagger}, P=0.03$ (paired $t$-test); ${ }^{\ddagger}, P<0.001$ (paired $t$-test).
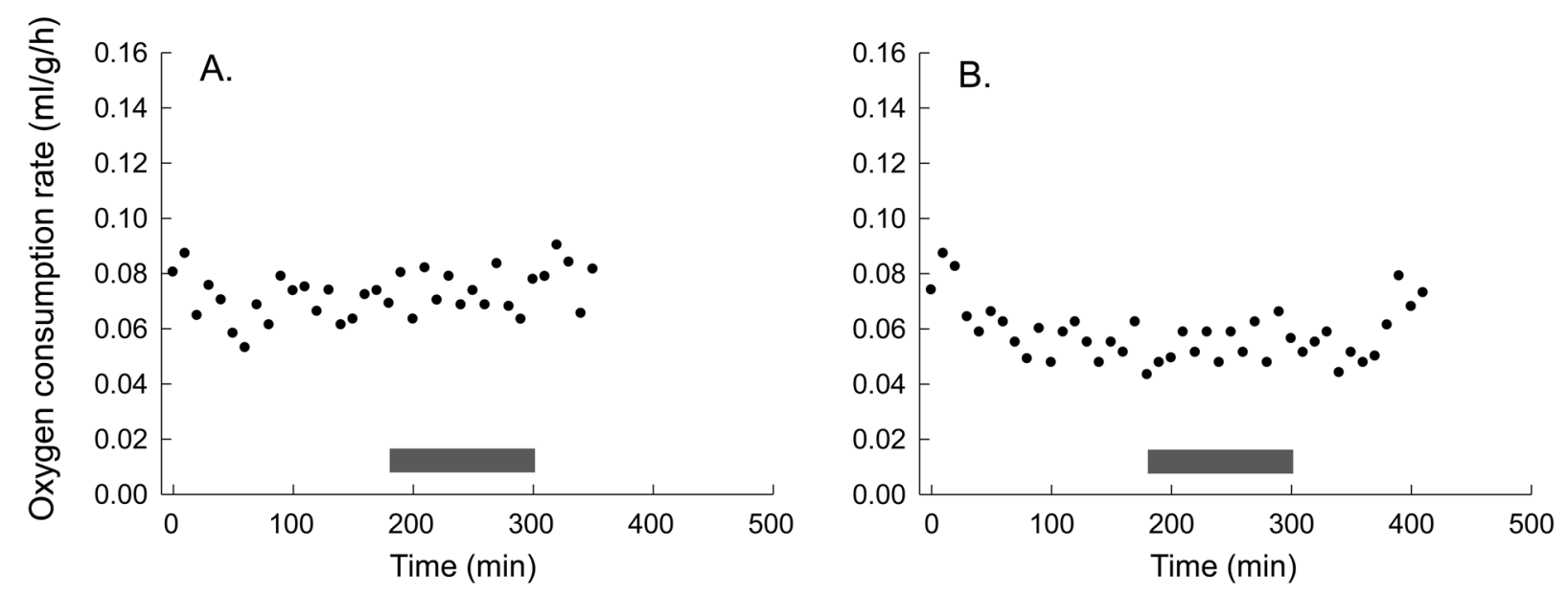

Fig. 2. Typical records of oxygen consumption rates $\left(\mathrm{VO}_{2}\right)$ for a gecko injected with vehicle $(\mathrm{A})$ or $\mathrm{T} 1 \mathrm{AM}$ (B). Note that the subject in either treatment showed relatively stable levels of $\mathrm{VO}_{2}$ for 180 to 300 min (indicated with gray bars) that were averaged and used as a representative value for that measurement.

counts $/ \mathrm{min}$ at $8 \mathrm{mg} / \mathrm{kg}$. After $400 \mathrm{~min}$ post-injection, the VR at these doses returned to a value at or above the control level. The VR remained at $5 \sim 9$ counts/min for up to $930 \mathrm{~min}$ at a dose of $16 \mathrm{mg} / \mathrm{kg}$ T1 AM (Fig. 1D. From these results, we chose a dose of $8 \mathrm{mg} / \mathrm{kg}$ as a suitable dosage of T1 AM and a 2-h time frame from 180 $\min$ to $300 \mathrm{~min}$ for the subsequent analyses. Under the influence of T1AM, the average and minimum VR decreased 0.64 - and 0.33 -fold, respectively, compared with the control VRs (independent $t$-test, $P<0.001$ ) (Table 1).

The $\mathrm{VO}_{2}$ was determined using six subjects treated with and without T1AM (Fig. 2). The average $\mathrm{VO}_{2}$ was 0.072 when the animals were treated with only the vehicle, but it decreased 0.76 -fold for the same animals injected with T1 AM (paired $t$-test, $P=0.03$ ) (Table 1).

Figure 3 illustrates the experimental apparatus with a gecko on a copper plate that displayed a thermal gradient between $5^{\circ} \mathrm{C}$ and $45^{\circ} \mathrm{C}$ (A to $\mathrm{C}$ ). Figures $3 \mathrm{D}$ and $3 \mathrm{E}$ presents typical $\mathrm{T}_{\mathrm{b}}$ readings over $\sim 400 \mathrm{~min}$ post-injection for two animals, each with and without T1AM treatment. The $T_{b}$ profile was nearly identical in both conditions for up to 180 min post-injection. The $\mathrm{T}_{\mathrm{b}}$ values subsequently diverged, with the subjects treated with T1AM showing lower $\mathrm{T}_{\mathrm{b}}$ ranges. With the T1AM treatment, the average upper limit (UL) of the PBT decreased from $31.9^{\circ}$ to $30.6^{\circ} \mathrm{C}$, and the lower limit (LL) decreased from $29.5^{\circ}$ to $26.3^{\circ} \mathrm{C}$ (paired $t$-test for both UL and LL, $P<0.001$ ) (Table 1). 

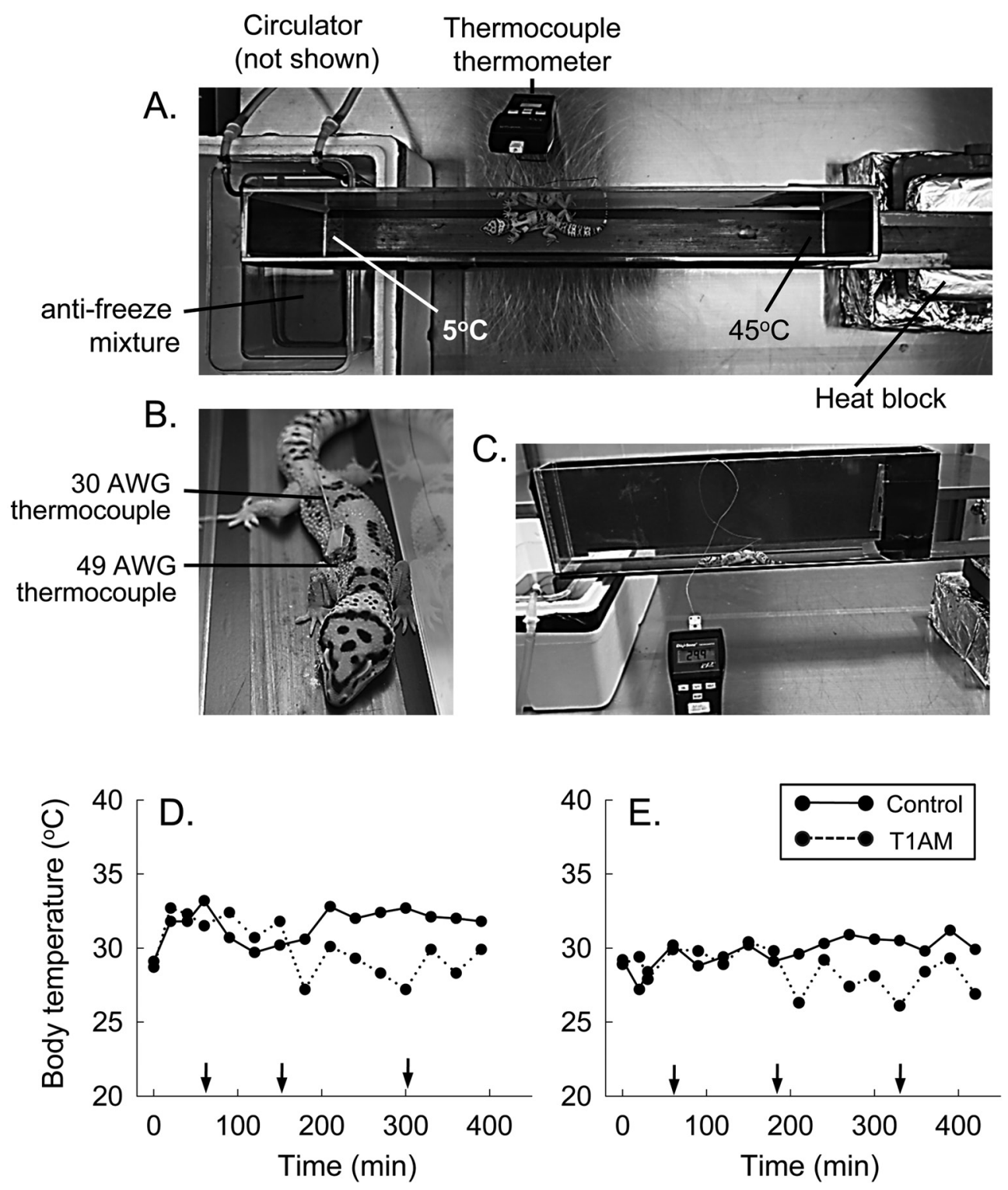

Fig. 3. An experimental setting for measurements of the PBT of the lizards over a thermal gradient between $5^{\circ} \mathrm{C}$ and $45^{\circ} \mathrm{C}$. (A) Top view showing the whole apparatus. (B - C) A gecko moving along the copper plate. The sensing tip of the $49 \mathrm{AWG}(0.025 \mathrm{~mm}$ diameter) thermocouple (barely visible) connected to the $30 \mathrm{AWG}$ thermocouple was inserted into a dorsal muscle to measure its $\mathrm{T}_{\mathrm{b}}$. (D and $\mathrm{E}$ ) Typical records of $\mathrm{T}_{\mathrm{b}}$ monitored from two lizards. Each lizard was tested on the copper plate with injection of DMSO (control) or T1AM (see the details in Materials and Methods). A subject shown in $\mathrm{D}$ was placed on the warmest end of the copper plate $\left(45^{\circ} \mathrm{C}\right)$; a subject shown in $\mathrm{E}$ was placed on the coolest end of the plate $\left(5^{\circ} \mathrm{C}\right)$. Black arrows on both the $\mathrm{x}$-axes show the time points at which the subject moved to other thermal regions.

\section{Discussion}

Ectotherms respond to thermoregulatory demands primarily by behavioral means. These demands are adaptive since the optimal $\mathrm{T}_{\mathrm{b}}$ causes increases in reproductive, digestive and performance capacity $[7,20]$. The behavioral mode of response is observed even in the special case of fever in the lizard $D$. dorsalis. In this situation, the PBT range shifted to a higher level in the presence of a bacterial infection, resulting in a higher survival rate [18]. Thus, in light of the fundamental principle of thermoregulation, we investigated whether ec- 
totherms show the ability to attain hypothermia behaviorally.

We found that T1AM was effective for inducing hypoventilation and hypometabolism in the geckos. The average $\mathrm{VR}$ and $\mathrm{VO}_{2}$ were reduced 0.64 - to 0.76 -fold as a result of T1AM treatment (Table 1). These results suggest that the reptiles might have the same cellular mechanism to that of rodents for interaction of T1AM with its membrane receptors which then trigger hypometabolism. It is worth noting that the quantity of T1 AM required for the induction of hypometabolism in lizards was $1 / 6.25$ of the quantity required in mice ( 8 vs. 50 $\mathrm{mg} / \mathrm{kg}$ ) [14]. This difference may partly reflect the low $\mathrm{VO}_{2}$ of the lizards compared to mice $(0.072$ vs. 1.93 $\mathrm{ml} / \mathrm{g} / \mathrm{h})$ at the standard or normal $\mathrm{T}_{\mathrm{b}}[11]$.

Our final goal was to investigate whether the T1AMinduced hypometabolism was accompanied by behavioral hypothermia. The results of the experiment supported our hypothesis. The experiment furnished the first evidence that both the upper and lower limits of the PBT in lizards treated with T1AM were significantly lower than those of the same animals treated with only the vehicle DMSO. Because the subjects were free to move along the thermal gradient, it appeared that hypothermia was pursued behaviorally under the T1AM-induced hypometabolic state. This differential change in the PBT occurred at 150 to $180 \mathrm{~min}$ post-injection, the time at which T1 AM was fully effective for hypoventilation and hypometabolism (Figs. 1 and 2). Conversely, our results may imply that the lizards exploit a relatively low thermal environment and remain in a low $\mathrm{T}_{\mathrm{b}}$ range, as do mammalian hibernators, when reduction of metabolic rate is crucial for survival (e.g., during times of food shortage) $[2,3]$.

In conclusion, the T1AM-treated lizards voluntarily pursued behavioral hypothermia. This result is consistent with hypoventilation and hypometabolism. Although the adaptive significance of hypothermia was not directly explored in this study, a reduction of energy expenditure, with decreased VR and $\mathrm{VO}_{2}$, would be beneficial to ectotherms in certain conditions like food shortage. Our result provides valuable evidence that the principal thermoregulatory mechanism might be conserved in the same phylogenetic lineage including the domesticated reptiles as well as laboratory mice.

\section{Acknowledgments}

We are grateful to two anonymous reviewers for their time and kind comments that improved the paper very much. This research was supported by Basic Science Research Program through the National Research Foundation of Korea (NRF) funded by the Ministry of Education (2014R1A1A2056794) and in part by the Yonsei University Research Fund of 2015.

\section{References}

1. Blackstone, E., Morrison, M., and Roth, M.B. 2005. $\mathrm{H}_{2} \mathrm{~S}$ induces a suspended animation-like state in mice. Science 308: 518. [Medline] [CrossRef]

2. Campbell, H.A., Fraser, K.P., Bishop, C.M., Peck, L.S., and Egginton, S. 2008. Hibernation in an antarctic fish: on ice for winter. PLOS ONE 3: e1743. [Medline] [CrossRef]

3. Canale, C.I., Perret, M., Théry, M., and Henry, P.Y. 2011. Physiological flexibility and acclimation to food shortage in a heterothermic primate. J. Exp. Biol. 214: 551-560. [Medline] [CrossRef]

4. Carey, H.V., Andrews, M.T., and Martin, S.L. 2003. Mammalian hibernation: cellular and molecular responses to depressed metabolism and low temperature. Physiol. Rev. 83: 1153-1181. [Medline] [CrossRef]

5. Du, Y., Ding, G.H., Sun, Y.Y., and Ji, X. 2008. Northern grass lizards (Takydromus septentrionalis; Lacertidae) shift thermal preferences when fasted. Curr. Zool. 54: 739-743.

6. Forgan, L.G. and Forster, M.E. 2010. Oxygen consumption, ventilation frequency and cytochrome c oxidase activity in blue cod (Parapercis colias) exposed to hydrogen sulphide or isoeugenol. Comp. Biochem. Physiol. C Toxicol. Pharmacol. 151: 57-65. [Medline] [CrossRef]

7. Goller, M., Goller, F., and French, S.S. 2014. A heterogeneous thermal environment enables remarkable behavioral thermoregulation in Uta stansburiana. Ecol. Evol. 4: 33193329. [Medline] [CrossRef]

8. Hashiguchi, Y. and Nishida, M. 2007. Evolution of trace amine associated receptor (TAAR) gene family in vertebrates: lineage-specific expansions and degradations of a second class of vertebrate chemosensory receptors expressed in the olfactory epithelium. Mol. Biol. Evol. 24: 2099-2107. [Medline] [CrossRef]

9. Itoh, K., Watanabe, K., Wu, X., and Suzuki, T. 2010. Three members of the iodothyronine deiodinase family, dio1, dio2 and dio3, are expressed in spatially and temporally specific patterns during metamorphosis of the flounder, Paralichthys olivaceus. Zoolog. Sci. 27: 574-580. [Medline] [CrossRef]

10. Johansson, P. 1982. Central cardiovascular effects of L-DOPA and clonidine in the lizard, Agama caudospinosa. Acta Physiol. Scand. 116: 37-40. [Medline] [CrossRef]

11. Ju, H., So, H., Ha, K., Park, K., Lee, J.W., Chung, C.M., and Choi, I. 2011. Sustained torpidity following multi-dose administration of 3-iodothyronamine in mice. J. Cell. Physiol. 226: 853-858. [Medline] [CrossRef] 
12. Lee, M., Choi, I., and Park, K. 2002. Activation of stress signaling molecules in bat brain during arousal from hibernation. J. Neurochem. 82: 867-873. [Medline] [CrossRef]

13. Scanlan, T.S. 2009. Minireview: 3-Iodothyronamine (T1AM): a new player on the thyroid endocrine team? Endocrinology 150: 1108-1111. [Medline] [CrossRef]

14. Scanlan, T.S., Suchland, K.L., Hart, M.E., Chiellini, G., Huang, Y., Kruzich, P.J., Frascarelli, S., Crossley, D.A., Bunzow, J.R., Ronca-Testoni, S., Lin, E.T., Hatton, D., Zucchi, R., and Grandy, D.K. 2004. 3-Iodothyronamine is an endogenous and rapid-acting derivative of thyroid hormone. Nat. Med. 10: 638-642. [Medline] [CrossRef]

15. Swan, H. and Schätte, C. 1977. Antimetabolic extract from the brain of the hibernating ground squirrel Citellus tridecemlineatus. Science 195: 84-85. [Medline] [CrossRef]

16. Tatro, J.B. 2000. Endogenous antipyretics. Clin. Infect. Dis.
31:(Suppl 5): S190-S201. [Medline] [CrossRef]

17. Terrien, J., Perret, M., and Aujard, F. 2011. Behavioral thermoregulation in mammals: a review. Front. Biosci. (Landmark Ed.) 16: 1428-1444. [Medline] [CrossRef]

18. Vaughn, L.K., Bernheim, H.A., and Kluger, M.J. 1974. Fever in the lizard Dipsosaurus dorsalis. Nature 252: 473-474. [Medline] [CrossRef]

19. Wang, Z.X., Wu, Z.J., Yu, H., Huang, C.M., and Zhong, Y.M. 2008. Thermoregulatory and thermal dependence of resting metabolic rates in the Chinese crocodile lizard Shinisaurus crocodilurus in the Luokeng Nature Reserve, Guangdong. Curr. Zool. 54: 964-971.

20. Zhao, Q., Wang, Z., Liu, L.L., Zhao, W.G., and Ji, X. 2008. Selected body temperature, surface activity and food intake in tailed versus tailless Mongolian racerunners Eremias argus from three populations. Curr. Zool. 54: 60-66. 